\title{
Remembering Deese's 1959 articles: The Zeitgeist, the sociology of science, and false memories
}

\author{
DARRYL BRUCE \\ Saint Mary's University, Halifax, Nova Scotia, Canada \\ and \\ EUGENE WINOGRAD \\ Emory University, Atlanta, Georgia
}

\begin{abstract}
Two contemporaneous reports by J. Deese-one concerned with correct recall (1959a), the other with recall intrusions (1959b)-have differed dramatically in their citations to date. The differences represent an unusually compelling instance of the operation of the scientific Zeitgeist. The article dealing with correct recall was congruent with the Zeitgeist of memory research when it was published. Hence it flourished. Just the opposite was true of the article on intrusions, which by the mid 1970s had gone into eclipse. A markedly different Zeitgeist in the $1990 \mathrm{~s}$, however, led two investigators simultaneously and independently to adapt Deese's intrusion method to the investigation of false memories.
\end{abstract}

Boring (e.g., 1959/1963b, 1963a) has argued that the Zeitgeist is the primary determinant of developments in science. By the Zeitgeist of a science is meant its prevailing theories, facts, problems, and methods, as well as the values, opinions, and attitudes of its practitioners and the societal context in which it functions. This climate of thought and opinion, Boring contended, both advances and hinders the emergence of scientific ideas and procedures. Merton's (e.g., 1961/1973b) research led him to a similar position, one that he referred to as the sociological theory of scientific development. Such views do not ignore the influence of great minds on the course that a science may take; rather, the collective scientific and social environment is seen as a more potent force.

Two kinds of events testify to the hypothesis. One is what may be called an anticipation (cf. Sarup, 1978): An innovation-a correct scientific idea, a useful method, or a significant finding - when first introduced, receives little or no attention. At some later time, however, it meets with a favorable reception. The explanation from the per-

We thank Harry Bahrick, Robyn Fivush, Elizabeth Loftus, Don Read, Roddy Roediger, and Roger Thomas for helpful criticisms of an earlier version of the essay. We also thank the following individuals for patiently replying to our numerous queries: John Barresi, Douglas Bernstein, James Deese, Randy Engle, Jim Jenkins, Colleen Kelley, Elizabeth Loftus, Bill McKeachie, Don Read, Roddy Roediger, Dan Schacter, and Endel Tulving. The manuscript was written while the first author was on sabbatical leave at Emory University; the hospitality of the Department of Psychology at Emory is gratefully acknowledged. Financial support was provided by the Emory Cognition Project and the Social Sciences and Humanities Research Council of Canada. Correspondence about this article may be sent to D. Bruce, Department of Psychology, Saint Mary's University, Halifax, NS, B3H 3C3 Canada (e-mail: dbruce $a$ huskyl.stmarys.ca) or E. Winograd, Department of Psychology, Emory University, Atlanta, GA 30322 (e-mail: genew@fs $1 . p s y$. emory.edu). spective of the Zeitgeist is that in the first instance, the times were not congenial to the new information, but later on they were. It is not difficult to produce examples that may be interpreted in this way. A classic one is the proposal by Aristarchus (ca 260 B.C.) that the earth is not the center of the universe but just another planet that revolves about the sun. Notwithstanding the correctness of that view, it failed to gain currency. Some 1,800 years passed before the times changed sufficiently and the heliocentric theory of Copernicus, published in 1543, carried the day. A more recent example is Mendel's theory of the elements of heredity - what we now call genesand the manner of their transmission from parents to offspring. Mendel published his work in 1866, but his report went ignored until 1900, when three botanistsCorrens, de Vries, and Tschermak - independently published papers to the same effect only to find to their chagrin that they had been anticipated by Mendel. The explanation of why Mendel's contributions went neglected for so long is complex, but a significant factor was that he was ahead of the knowledge and the evolutionary problems of his time (Mayr, 1982). In sum, the Zeitgeist can delay the emergence of a new scientific idea and then later facilitate its acceptance.

The second kind of event that points to the influence of the Zeitgeist is the simultaneous and independent emergence of a scientific discovery - a new finding, method, theory, or application advanced by two or more individuals, working independently, at about the same time. Such events are termed multiples (e.g., Boring, 1963a; Merton, 1963/1973a). They

suggest that discoveries become virtually inevitable when prerequisite kinds of knowledge and tools accumulate in man's cultural store and when the attention of an appreciable number of investigators becomes focused on a prob- 
lem, by emerging social needs, by developments internal to the science, or by both. (Merton, p. 371)

Examples of multiples in science are easy to come by. One, and undoubtedly the most famous, is Darwin and Wallace's independent and roughly simultaneous proposal in the mid-1800s of natural selection as the mechanism of evolution. Another is the hypothesis of continental drift. Hallam (1973) reported that it was first developed and advanced by Taylor in 1910 and then independently and more extensively by Wegener in a series of publications beginning in 1912. The simultaneous and independent triple rediscovery in 1900 of Mendel's work also qualifies as a multiple. If we add Mendel's original report of 1866 to the mix, of which the rediscoverers were unaware, we have a delayed quadruple (Merton, 1961/1973b).

The field of memory is not without its anticipations and multiples. The negative recency effect is an instance of the former. When it was reported by Craik in 1970, it was immediately and widely appreciated as an effective argument against single-store memory theory. We now know from the work of Madigan and O'Hara (1992) that the effect had actually been observed roughly 70 years earlier by Calkins (1898). But lacking a scientific context at the time to give it any moment (Calkins herself made little of it), speedy oblivion was its inevitable fate. Yet another illustration of an anticipation is Richard Semon's extensive analysis of retrieval processes 70 years before contemporary investigators such as Tulving (1976, 1983 ) focused attention on retrieval once again. (See Schacter, 1982; Schacter, Eich, \& Tulving, 1978, for a full treatment of Semon's contributions and the reasons for the neglect of his work.) An example of a multiple is the distractor procedure for assessing short-term memory. Memory researchers implicitly recognize it as such, referring to it as the Brown-Peterson task (e.g., Crowder, 1976) after Brown (1958) and Peterson and Peterson (1959), who independently introduced it.

Though testimony to the operation of the Zeitgeist by way of historical examples seems persuasive, such evidence is not always as unexceptionable as one would like. Documentation of details of the Zeitgeist surrounding anticipations or multiple discoveries is often unrevealing, fragmentary, or entirely lacking and irrecoverable with the passage of time. Furthermore, individuals who were part of a historical Zeitgeist or central to a scientific discovery or an anticipation from long ago are unlikely to be available to furnish their recollections and reflections. Hence a contemporary example of the operation of the Zeitgeist without such drawbacks and possessing additional advantages could be more compelling.

Just such an example has come to our attention. It is a case history of research on memory, and it has a number of attractive features that merit its careful consideration. First, it illustrates both kinds of evidence for the Zeitgeist that we have discussed: research initially at odds with, but later favored by, the Zeitgeist, and simultaneous and independent discovery by two investigators. Second. the case rather fortuitously includes parallel research that serves as a comparison for evaluating the influence of the Zeitgeist. Third, those who have been involved in the research have been willing to comment on it. Such evidence is particularly useful in illustrating the psychology and sociology of science. Fourth, the Zeitgeist includes broader societal concerns and these too have played a role in the present instance. Finally, ample documentation exists, some of it quantitative, concerning the Zeitgeist and its changes during the period under examination. For all these reasons, we put forth the present case as paradigmatic of the functioning of the Zeitgeist.

\section{An Overview of Deese's (1959a, 1959b) \\ Memory Research and Its Recognition}

In 1959, James Deese published two complementary articles on memory. The first, in Psychological Reports (Deese, 1959a), showed that correct free recall of a list of words is directly proportional to interitem associative strength - the mean relative frequency with which each list word elicits all other list members as free associates. We hereafter refer to this publication as the numbercorrect article. The second paper (Deese, 1959b), which appeared a month later in the Journal of Experimental Psychology, reported that the probability of incorrectly recalling a word that had not been presented (an intrusion) was directly proportional to the degree to which that word occurs on the average as an association to the words that were presented. Thus, if the words of a list converge associatively on sleep, then sleep tends to be produced in free recall even though it was not on the list. Hereafter, this publication will be referred to as the intrusion article.

Both reports were timely. They appeared when interest in free recall and memory was on the rise (e.g., Broadbent, 1958; Miller, 1956; Murdock, 1962; Waugh \& Norman, 1965). Yet the two publications have had strikingly different citation histories. Figure 1 graphs their cumulative citations from 1959 through 1997 according to the Science/Social Sciences Citation Index. The numbercorrect article published in the lower impact journal, $P$ sychological Reports, was frequently cited up to the mid $1970 \mathrm{~s}$ before settling down to a steady rate of about $1 \mathrm{ci}$ tation per year. The intrusion article, despite its appearance in the more prestigious Journal of Experimental Psychology, never really got out of the gate. By the late 1970s and up through the end of 1994, its citation rate had declined to approximately 0 per year. Total citations for the number-correct article to the end of 1994 were 145; for the intrusion article, $34{ }^{1}$

From 1995 to 1997 , however, fortunes changed for the intrusion paper as citations more than doubled over the level reached by the end of 1994. The reason was Roediger and McDermott's (1995) adaptation of Deese's (1959b) procedure to create false memories for study in the laboratory. In addition to examining the intrusion of thematically related but nonpresented words in immedi- 




Figure 1. Cumulative citations from 1959 to 1997 of two articles by Deese, one on number correct (1959a) and the other on intrusions (1959b).

ate free recall, Roediger and McDermott also assessed their false recognition and asked for remember-know judgments (Gardiner \& Java, 1993; Tulving, 1985). This led to greater awareness of Deese's intrusion article, which is reflected in the acceleration of its citations in 1996 and 1997.

The questions of present interest are why so little attention was paid early on to Deese's (1959b) article on intrusions and what brought about its recent renaissance. The easy answer is that the memory Zeitgeist of the $1960 \mathrm{~s}$ and thereafter was unreceptive and even counter to the intrusion article and that just the opposite was true in the 1990s when false memories became an important problem. Deese himself saw it that way:

The fact that the article did not receive the attention it deserved is mainly my fault, but it was also the zeitgeist. ... [the investigation of] false memories had not yet come into its own, and I did not have the sense to realize the importance of the problem. (personal communication, January 13,1997 )

Though the hypothesis is plausible, we will present a more detailed case for it: What were the particulars of the Zeitgeist of memory research in the 1960s that worked against a more favorable reception of Deese's (1959b) intrusion paper? What accounts for the greater attention given to the number-correct article (Deese, 1959a)? Why in the 1970s, when the Zeitgeist of memory research became more aligned with what the intrusion article had to offer, did it still go unappreciated? What exactly were the details behind the revival of interest in the Deese procedure in the 1990s? The answers to these questions describe how the Zeitgeist inhibited and facilitated the recognition of Deese's two articles.

The application of Deese's (1959b) intrusion method to the study of illusory memories is especially interesting for what it reveals about the process of scientific discovery. The revival of Deese's procedure was not simply an instance of a method whose time had come. The heightened concern in this decade about false memories was undoubtedly essential, but the procedure had to be discovered-in other words, recognized as useful to the laboratory study of such memories. The behind-the-scenes story nicely illustrates the point. It also reveals that the idea occurred independently and at more or less the same time to two research scientists, thus indicating the other kind of evidence that this case furnishes for the Zeitgeist-namely, its status as a multiple.

\section{What Deese Did, What He Said, and What He Did Not Say}

We turn now to the content of Deese's two 1959 articles. The number-correct paper (Deese, 1959a) was published first, although it was actually written second. It deals with two major questions. The first is the extent to which the number of words recalled is a function of interitem associative strength as indexed by word associa- 
tion norms. The second question is one that may seem odd to the contemporary student of cognition but was regarded as important at the time: Is clustering in free recall mediated by organizational strategies or does associative strength have a direct - that is to say, unmediated - effect on recall? As Deese put it, if the effect is direct, then "in part, free recall may be described as free association" (p. 306). To gain insight into the problem, Deese manipulated whether or not an appropriate cue-the stimulus word for the list-was present at study.

To construct his lists, Deese (1959a) used the Minnesota norms (Jenkins, 1970; Russell \& Jenkins, 1954), which provide the probabilities of various word associations to the Kent-Rosanoff stimuli. Kent and Rosanoff (1910) chose 100 common nouns and adjectives and presented them to 1,000 subjects to obtain baseline data for normal subjects to serve as a comparison for ascertaining abnormal association patterns. These norms, updated by Jenkins and his colleagues, are still used by researchers. Deese's lists were composed of high-frequency associates to a particular stimulus word, low-frequency associates, or zero-frequency associates. A test of immediate free recall followed each list. The cuing manipulation involved presenting at study either the stimulus word appropriate for that list or, instead, an irrelevant word. In a parallel procedure with another set of subjects, Deese obtained word-association norms for each of the list items to determine interitem associative strength-- that is, the average probability that each item on a given list would elicit each of the other 14 items on the list.

Deese (1959a) first reports that the number of items recalled was greatest for the lists composed of high-frequency response words and lowest for the zero-frequency lists. The major finding was that the correlation across all lists between the number of words recalled and mean interitem associative strength was .88 . The tighter the associative structure of a list, then, the more words recalled. Associative structure also had an effect on intrusions. Here, the tighter the associative structure, the fewer the intrusions - the correlation between intrusions and interitem associative strength was -.48 . The other result of interest was that the provision of an appropriate list name had no effect on recall. Deese favored "an interpretation of free recall in terms of free association.... [which] is probably a direct, unmediated activity with little or no active editing of the material being recalled" (p. 312). In other words, he saw no need to invoke organizational processes to account for the data; they could all be explained in terms of horizontal associations.

The second paper (Deese, 1959b) has as its sole concern accounting for intrusions. Deese noted two problems in the investigation of intrusions: first, how to produce them reliably, and second, "to demonstrate that they are accounted for in terms of simple association" (p. 17). To this end, Deese again constructed lists from Russell and Jenkins's (1954; Jenkins, 1970) norms. This time he took the 12 most frequent word associations to 36 Kent-
Rosanoff stimuli (e.g., sleep and butterfly). The resulting thirty-six 12-item lists were presented to each subject, and memory was tested after each list by free recall. Next, Deese obtained from a separate sample of subjects his own word-association norms for the 400 or so words making up the 36 lists. This was necessary to determine backward association probabilities - that is, from list items to the 36 stimuli. To use the sleep list as an example, Deese needed to know the likelihood that each of the 12 words on the list elicited sleep. He then calculated the mean of these percentage frequencies. For the 36 lists, the range of means was roughly $0 \%-30 \%$.

Remarkably, Deese (1959b) presents no description of correct recall-not only is this paper about intrusions, it is only about intrusions. Equally surprising is the fact that the major dependent variable is a correlation: The probability of the stimulus word occurring as an intrusion correlated .87 with its probability as an association to the list items. ${ }^{2}$ Although Deese (1959a) reported an equally astounding correlation of 88 between correct recall and interitem associative strength in the numbercorrect paper, he made more of the correlation in this instance, emphasizing that he accounted for $76 \%$ of the variance with a single independent variable. Unlike in the other study, here he predicted specific intrusions, a more considerable achievement. Indeed, Deese was so impressed by the power of this manipulation that he pointed out that, on the basis of the linear regression equation obtained, if he were to create a list for which the mean associative frequency of a word were $60 \%$, that word would occur as an intrusion with a probability of 1.0. With regret, he acknowledged that he did not succeed at this task (although he tried), given the limitations of the available norms and the use of 12-item lists.

It is of especial interest that Deese (1959b) related his findings to Bartlett's (1932) work. His results provide, he suggested, "an important mechanism" (p. 21), word association, for explaining the kinds of memory errors observed by Bartlett. As an example, Deese examined one of Bartlett's protocols from the "War of the Ghosts," in which a subject intruded the words battle and enemy. The word war appears four times in the story as well as once in the protocol, followed by the two intrusions. Deese noted that battle and enemy are, in fact, predictable intrusions as high-frequency associates to war.

In summary, Deese adopted a straightforward associationism in his 1959 articles. Simple associative frequencies could account for both number correct and errors in free recall and even elaborative effects such as those described by Bartlett. No appeal to hierarchical organization or constructive processes was necessary.

\section{Why the Difference in the Early Reception of Deese's Two Articles?}

How now does one explain the modest response to Deese's (1959b) investigation of intrusions in free recall, at least as indicated by the few times it was cited over the 
first 15 years or so of its existence? Roediger and McDermott (1995) found such neglect surprising, given that single-trial free recall "was just gaining favor among experimental psychologists at that time and was the focus of much attention during the $1960 \mathrm{~s}$ " (p. 804). The puzzle is heightened by the far greater number of citations of the number-correct paper (Deese, 1959a), which, as we have seen, has many methodological similarities to the intrusion article and was published in a much less prestigious journal.

It is probable that the explanation of the difference in the citations of the two reports has much to do with their different dependent variables: number correct and intrusions. That difference mirrors the relative emphases given to accurate and inaccurate remembering since the inception of experimental research on memory in 1885 . The contrast has been noted by Roediger (1996; Roediger, McDermott, \& Robinson, 1998) and is personified in the investigative traditions spawned by Ebbinghaus (1885/1964) and Bartlett (1932). As is well known, Ebbinghaus favored rote learning, usually followed by relearning, of lists of nonsense syllables, and he offered associative explanations of his findings. Bartlett opted to use more meaningful materials such as short stories, newspaper reports, and pictures, and he interpreted the recollective errors of his subjects as evidence for schemas and reconstruction in memory. Memory researchers following the lead of Ebbinghaus have focused on correct remembering; those going down the path of Bartlett have stressed errors in remembering to demonstrate that memory is largely a schema-driven reconstructive process. The Ebbinghaus orientation was the dominant one until the early $1970 \mathrm{~s}$, at which time Bartlett's ideas began to take hold; citations of Bartlett's book Remembering show a particularly steep increase from 1972, when there were only 16 citations, through 1979 , a year in which there were 105 .

The argument, then, is that the divergent cumulative citation frequencies of the two Deese articles are due in large measure to how they happened to mesh with the contrasting approaches of Ebbinghaus and Bartlett and the favor that each has found over the years. The article investigating number correct (Deese, 1959a) received a respectable initial reception because it squared with the dominant Ebbinghaus tradition of the day. The study of extralist intrusions (Deese, 1959b), by contrast, did not. Indeed, Deese noted in the introduction to the intrusion paper that no scheme for predicting such errors had heretofore been developed. Thus it is not surprising that the one that he provided in this article, despite being supremely associative, aroused little interest. As well, the implications that Deese (1959b) drew from his intrusion data for understanding the kinds of inaccuracies that Bartlett (1932) reported in the recall protocols of his subjects found even less of an audience, for Bartlett's research was largely invisible to the memory community at that time. In fact, the sole citation of Bartlett's (1932) book in 1959 appeared in Deese's intrusion article.
If this line of reasoning is correct, one may wonder why the intrusion paper was accepted for publication in a more prestigious establishment periodical-Journal of Experimental Psychology-and the number-correct report in a lesser journal-Psychological Reports. Obviously our story would have been tidier had it been the other way around. Deese's account of how this happened (personal communication, January 13, 1997) was that he sent the intrusion manuscript, which was written first, to the Journal of Experimental Psychology but with little hope for its prospects because of past difficulties in getting his work published there. Nevertheless, the editor at the time, Arthur Melton, accepted the paper (though Deese remembers that he did so grudgingly (personal communication, April 1, 1997). ${ }^{3}$ As for the report of the number-correct research, Deese submitted it to Psychological Reports to avoid the problems that he had regularly encountered in getting his work into the Journal of Experimental Psychology (personal communication, January 13, 1997). In short, the appearance of the less frequently cited of Deese's 1959 articles in the more significant journal and vice versa should not be seen as weakening our hypothesis that the difference in the initial reception of the two papers reflects their fit to the prevailing research Zeitgeist.

Before concluding this section, we must take up an influential article on memory errors published in 1965 by Underwood. Using a continuous recognition task, he found an increase in false alarms to distractor words when they were associatively related to earlier studied target words. Through 1994, Underwood's paper was cited 186 times, more than five times as often as Deese's (1959b) intrusion study, and this despite its having appeared 6 years after Deese's paper.

Broadly speaking, both investigations focused on errors. Why then the greater attention to Underwood's (1965) article? To begin with, it is not that its timing was better vis-à-vis an increasing recognition of Bartlett (1932). Bartlett was still underappreciated in 1965; that year there were only 8 citations of his 1932 book. Moreover, Underwood made no mention of Bartlett in his paper. Rather, Underwood's investigation may have garnered the attention it did because its concern was the development of verbal learning theory. The interpretation of the greater number of false alarms when lures were associatively related to target words was that such lures actually occurred as implicit associative responses to the target words when they were studied initially. Hence the distractor words would be likely to be misjudged as having been presented earlier. Underwood's article provided, then, presumptive evidence that subjects engaged in the kind of implicit responding that was being proposed in verbal learning theory of the day (e.g., mediation in the explanation of transfer phenomena in paired-associate leaning).

To summarize, Deese's (1959b) intrusion paper failed to find much of an audience initially because it seemed to contribute so little toward understanding the dominant Ebbinghausian problem of the day - correct recall. It offered instead an explanation of recall errors in terms of 
elementary associative habits, and it even proposed that such a mechanism could handle the kinds of elaboration and change that Bartlett (1932) had observed in his subjects' recollections. Neither problem was much of an issue at the time. No matter also that Deese's study used the method of free recall, which was becoming increasingly popular by the $1960 \mathrm{~s}$. Insofar as Bartlett's ideas were concerned, advocates of that method seemed little more moved by them than were earlier adherents of serial and paired-associate learning. For example, Tulving's (1968) authoritative essay, "Theoretical Issues in Free Recall," did not mention Bartlett. On the other hand, the far greater attention paid to Deese's (1959a) article, emphasizing as it did correct recall and even a horizontal associative interpretation of the process, was far more in keeping with the prevailing memory Zeitgeist.

\section{Why No Renaissance of Deese's Intrusion Article With the Increasing Appreciation of Bartlett's (1932) Research?}

Though the argument to this point explains the striking early difference between the cumulative citation functions for the two Deese articles, it does not account for the fact that when Bartlett's (1932) approach came into fashion in the $1970 \mathrm{~s}$, citations of the intrusion publication (Deese, 1959b) did not pick up. It is possible, of course, that by then it had simply fallen though the cracks never to be recovered. More than that was involved, we believe.

Three characteristics of the literature in cognitive psychology of the late 1960 s and early 1970 s appear to have moved Bartlett (1932) to center stage. Two of them reflect his theoretical ideas, and the third echoes his methodological approach. The first of the theoretical notions was the schema, which was central to the perceptual learning research of Posner and Keele (1968), the formation of linguistic idea sets by Bransford and Franks (1971), and the cognitive psychology of Neisser (1967). The other theoretical proposal stemming from Bartlett was the constructive and reconstructive nature of memory, a perspective that was forcefully advocated by Neisser, again in his defining treatment of cognitive psychology. As for Bartlett's method, he adopted materials resembling those met with in everyday life: folk stories, newspaper reports, pictures of faces, and the like. That too was characteristic of much memory research of the 1970 s that investigated schemas and reconstruction: Sentences, prose passages, and action sequences presented via slides or videotape were favored, although the use of dot patterns (e.g., Posner \& Keele, 1968) seems rather a departure from the script. As Roediger and McDermott (1995) have suggested, the preference for such materials may have been due to the belief that they permitted the operation of schematic and reconstructive processes to a greater degree than did lists of words.

Deese's (1959b) investigation of intrusions differed from Bartlett's (1932) studies on all three of these counts.
First, and perhaps most obvious, Deese used word lists. A more subtle difference was that Deese offered his results as a way of explaining the "kinds of elaboration in memory" (p. 21) that Bartlett observed, but he stopped short of calling them constructive or reconstructive changes. A greater theoretical divide between Deese and Bartlett, however, lay in the purely associative nature of Deese's interpretation:

The hypotheses arising out of the empirical relationship found in this study suggest ways of interpreting a wide variety of problems of patterning and organization in memory in terms of elementary associative frequencies. (Deese, 1959b, p. 22)

In sum, no aspect of Deese's (1959b) research would have appealed to those sympathetic to Bartlett's orientation-not Deese's materials, not his apparent lack of enthusiasm for the idea of reconstruction, and certainly not his suggestion that schemas and reconstruction might be based on "elementary associative frequencies," a proposal quite antithetical to Bartlettians. Thus it is no surprise that Posner and Keele (1968), Bransford and Franks (1971), and Neisser (1967), or for that matter, anyone else who favored Bartlett's views, did not cite Deese's intrusion paper. Neisser came close (p. 289), but he cautioned against appealing to word association frequencies as a way of understanding schemata. ${ }^{4}$

\section{The Application of the Deese Intrusion Procedure to the Investigation of Illusory Memories}

We come now to the discovery of Deese's (1959b) method for investigating recall errors. Our use of the word discovery requires clarification. For present purposes, it means the application of Deese's method to the experimental study of false memories and not simply an awareness or even use of the method itself. As we shall see, there was already considerable awareness and some informal use of the procedure at the time it was discovered. Who then may we credit with that discovery? To begin with, there can be little debate that it was Roediger and McDermott (1995) who put Deese's intrusion procedure on the map as a way of studying the creation of illusory memories. Nevertheless, two questions are of interest: First, how did Roediger and McDermott come across the method? Second, what if they had not? Would it have come to the attention of someone else and, far more critical, been applied to investigate false memories? The working of the Zeitgeist leads us to expect that it would have.

From Deese (1959b) to Roediger and McDermott (1995). In a footnote to their article, Roediger and McDermott thank Endel Tulving for bringing the Deese paper to their notice. That Tulving was the source is not altogether surprising. He mentioned the investigation in his important (1968) review of free recall, proposing that Deese's intrusions reflected remembered associations made to list words during study and not associative constructions during recall. In this interpretation, Tulving 
was in agreement with the position of Underwood (1965) described earlier. Roediger ventured to say that he must have read that suggestion several times, because as a graduate student in the early 1970 s, he had practically memorized Tulving's chapter (personal communication, December 24, 1996).

But the Zeitgeist then was clearly not such as to have led Roediger to make a great deal of Deese's (1959b) finding, for that is not how he remembers becoming aware of it:

I first heard of the Deese paper in the spring of 1993. Endel was giving a colloquium at Rice. ... During the question period, someone asked a question and, in the course of answering, for some reason Endel mentioned that Deese had done experiments where people had gotten words related to sleep and then recalled sleep with a high probability. I tucked that little nugget away in the back of my mind and later looked up the paper. (personal communication, November 20, 1996)

The first experiment of the Roediger and McDermott (1995) article was conducted in the fall of 1993 with "amazing results" (H. L. Roediger III, personal communication, November 20,1996). Experiment 2 was carried out in the spring of 1994. The manuscript was written in the summer of that year, submitted in August, and accepted for publication in December. The research was also reported at the 1994 meeting of the Psychonomic Society.

From Deese (1959b) to Read (1996). By the fall of 1993 - actually before Roediger and McDermott (1995) had begun to collect their data-Read already had the results in hand from two investigations of false memories using one of Deese's lists. The findings were reported at a conference on memory trauma at Clark University in December of that year (Read, 1993). They were also sketched in an article by Lindsay and Read (1994; accepted for publication September 20,1993) on psychotherapy and recovered memories of sexual abuse, albeit absent any reference to Deese (1959b). Not until 1996, however, did Read publish a complete account of his research.

How did he become aware of Deese's procedure and perceive its value to the investigation of false memories?

I had used the procedure for several years as a demonstration of the ease of producing false memories (the kind of déjà vu thing). I got it from the Appleby (1987) chapter in one of the APA Teaching Handbooks .... and was continually amazed as to its robustness. (personal communication, November 18, 1996)

It turns out that many other psychologists were familiar with the Deese method as a teaching demonstration. Roediger (personal communication, December 24, 1996) mentioned that Tulving had used it for that purpose. An introductory psychology demonstration prepared by Douglas Bernstein produces intrusions in the manner that Deese did and has been widely distributed - to the first author among others. Colleen Kelley (personal communication, December 30, 1996) reported that she had used Deese's procedure as a class demonstration and that it ac- companies the teaching materials for Myers's (1986) introductory psychology textbook. Most revealing were the comments of Randall Engle (personal communication, May 15, 1997). He has regularly employed the sleep list as a demonstration since 1969 , and he told us that he got it from Deese's (1967) introductory psychology text. Engle went on to remark that it never dawned on him that a false memory was being created by Deese's sleep list, only that an implicit associative response (Underwood, 1965) had occurred and was being remembered. Engle's observation illustrates the key point in all this: Many people, certainly many more than we have mentioned here, knew of Deese's method by which recall intrusions could be produced reliably, and many quite intimately through using it as a teaching tool, long before the appearance of Roediger and McDermott's (1995) report. But no one seems to have grasped how effectively it could be employed to investigate rigorously and systematically the creation of illusory memories. Indeed Appleby (1987), who provided one of the earliest examples of the demonstration, offered it as a way of creating the illusion of having experienced something before-a déjà vu impression-and not as a method for studying false memories.

It was initially only Roediger and Read who had that insight. What caused it? The element of surprise may have been critical. Both individuals noted how amazed they were by the effects that their variations on Deese's method produced. Intrusions in immediate free recall are ordinarily not all that frequent. With the strong associative structure of some of Deese's lists, however, they can occur as often as the recall of words that are on the list (Read, 1996; Roediger \& McDermott, 1995). Even more important, we believe, was the necessity for an important issue that the method might bear on. That issue was the false/recovered memory debate. Roediger's comment that upon hearing Tulving mention what Deese had done "I tucked that little nugget away in the back of my mind and looked up the paper" (personal communication, November 20,1966) implies a reason for perceiving the information as useful, else why would it be a "nugget"?

By 1993, the controversy about the validity of recovered memories of childhood sexual abuse was highly visible, both in the popular press and in psychology, leading to the appointment of a committee by the American Psychological Association in a vain attempt to resolve the debate. Within a relatively brief period, memory researchers became concerned with the question of memory inaccuracy. Special issues of journals devoted to the issue began to appear, for example, Applied Cognitive Psychology (Pressley \& Grossman, 1994) and the Journal of Memory \& Language (Nelson \& Roediger, 1996). A volume of conference reports on the problem of memory distortions was also published (Schacter, Coyle. Fischbach, Mesulam, \& Sullivan, 1995). The Zeitgeist had changed, largely because of external forces - specifically, societal concern about repressed and recovered memories and their validity. The times had thus become receptive to research on errors of memory, and the use of 
Deese's (1959b) lists having high probabilities of eliciting predictable intrusions could now be seen by Roediger and McDermott (1995) and Read (1996) as a simple yet effective laboratory approach to the problem. Thirtyfive years earlier, when Deese published his study of recall intrusions and the issue of false memories was on no one's radar scope, it could not have been so recognized.

In their experiments, Roediger and McDermott (1995) and Read (1996) proceeded independently. When and how did each of them become aware of the other's research? Roediger recalled that in mid-1994 "after Kathleen and I had finished our experiments . . . we learned that Read was on to something similar" (personal communication, April 30, 1997). The informant was likely Daniel Schacter (personal communication, January 19 , 1997) or Elizabeth Loftus (H. L. Roediger III, personal communication, November 20, 1996). For his part, Read remembered that Elizabeth Loftus alerted him in late 1993 that Roediger was using the Deese procedure to investigate false memories (personal communication, May 6, 1997) and that she urged him to move quickly to publish. He failed to do so, however, and Roediger and McDermott's paper appeared in 1995, before Read's full report in 1996.

\section{Who Discovered the Deese Intrusion Procedure?}

If by this question we mean who put Deese's (1959b) procedure into play as an experimental tool for probing the way in which false memories can arise, then the credit must surely go to Roediger and McDermott (1995). They published the first full-scale description of research on false memories using Deese's approach, they extensively cited and built upon his intrusion findings, and they observed memory errors with a number of different lists, in different experimental conditions, and on recognition as well as recall tests. On the other hand, Read actually reported his findings prior to Roediger and McDermott, though his reports were abbreviated and his results more limited, being based on the use of one list (the sleep list). As well, both Roediger and McDermott and Read perceived the usefulness of the Deese procedure in a way that others before them had not. Moreover, even though the two research teams completed their investigations without knowing what the other had done, their experiments show a notable similarity in the use of rememberknow judgments (Gardiner \& Java, 1993; Tulving, 1985). In the face of such data - and the data are sometimes far less compelling than these-historians generally consider the matter an instance of a multiple discovery and thus as evidence for the operation of the Zeitgeist. We believe we should do so here.

\section{Conclusion}

Deese published two investigations of memory in 1959 , one dealing with correct recall and the other with incorrect recall. The scientific reaction to the two articles over their lifetimes and the ultimate application of Deese's (1959b) intrusion method to the laboratory study of false memories presents an unusually clear and contemporary case for the operation of the Zeitgeist in memory research.
The facilitating and inhibiting influence of the Zeitgeist may be seen in the attention paid to the two reports. The article concerned with correct recall (Deese, 1959a) was well received because it was in accord with the dominant Ebbinghausian tradition of the day, which was aimed at understanding such recall. Conversely, the article about errors (Deese, 1959b), despite its appearance in a more prestigious journal, met with a tepid reception, and its attempt to account for recall errors and the kinds of elaboration observed by Bartlett was ahead of any substantial interest in such effects. When Bartlett's (1932) research came into vogue in the $1970 \mathrm{~s}$, Deese's intrusion paper continued to languish, now because it failed to square with Bartlett's theoretical and methodological orientation. Whereas Bartlett and those who followed in his wake emphasized the centrality of the schema and reconstruction in memory and the use of materials similar to those dealt with in daily life, Deese proposed interpreting Bartlett's results on simple associative grounds based on findings obtained with simple word lists. Such an approach was anathema to Bartlettians.

The revival of Deese's (1959b) procedure in the 1990s was not simply the use of a method whose time had come. It had to be discovered - that is, seen as advantageous to investigating and understanding illusory memories, which had become a significant societal problem. Many people were quite familiar with Deese's method and the effects it could produce. But few appeared to realize that it could be molded to rigorously studying the creation of false memories in the laboratory, and even fewer hastened to conduct such research. At more or less the same time, independently, and with some similarity in their efforts, Roediger and McDermott (1995) and Read (1996) did so. Independent simultaneous discoveries and research of this kind are often the outcome of a supportive scientific Zeitgeist, which ensures what in the present instance can now be seen reasonably clearly: If it had not been Roediger and McDermott, it would have been Read, and if it had not been Read, it would most likely have been someone else who, in using the Deese procedure as a class demonstration, perceived its effects as surprising - even "amazing"- and as a safe and effective way to study the occurrence of illusory memories in the laboratory.

Having argued that adapting Deese's method to the study of false memories represents a scientific multiple, we nevertheless recommend that those who use the method in the future refer to it as the DRM procedure, after Deese, Roediger, and McDermott. Labeling it so recognizes that the efforts of Roediger and McDermott (1995) were more substantive than those of Read (1996) in the revival of Deese's (1959b) approach. There is no inconsistency here. The constituents of a multiple, though coincident, need not have equivalent weight. Both Darwin and Wallace may have independently hit upon the idea of natural selection, but no one would dispute Darwin's greater claim to the hypothesis. Then, too, use of the DRM label may help prevent expressions such as "the standard Deese paradigm" or even "the Deese effect," which are attributions to Deese of what Roediger and McDermott did or found. 


\section{REFERENCES}

APPLEBy, D. (1987). Producing a déjà vu experience. In V. P. Makosky, L. G. Whittemore, \& A. M. Rogers (Eds.), Activities handbook for the teaching of psychology (Vol. 2, pp. 78-79). Washington, DC: American Psychological Association.

BARTLETT, F. C. (1932). Remembering: A study in experimental and social psychology. London: Cambridge University Press.

Boring, E. G. (1963a). Eponym as placebo. In R. I. Watson \& D. T. Campbell (Eds.), History, psychology, and science: Selected papers (pp. 5-25). New York: Wiley.

BORING, E. G. (1963b). Science and the meaning of its history. In R. I Watson \& D. T. Campbell (Eds.), History, psychology, and science. Selected papers (pp. 87-91). New York: Wiley. (Originally published 1959, The Key Reporter, 20 [4])

BRANSFORD, J. D., \& Franks, J. J. (1971). The abstraction of linguistic ideas. Cognitive Psychology, 2, 331-350.

Broadbent, D. E. (1958). Perception and communication. New York: Pergamon.

Brown, J. (1958). Some tests of the decay theory of immediate memory. Quarterly Journal of Experimental Psychology, 10, 12-21.

CALKINS, M. W. (1898). Short studies in memory and in association from the Wellesley College Psychological Laboratory: I. A study of immediate and of delayed recall of the concrete and of the verbal. Psychological Review, 5, 451-456.

Craik, F. I. M. (1970). The fate of primary memory items in free recall. Journal of Verbal Learning \& Verbal Behavior, 9, 143-148.

Crowder, R. C. (1976). Principles of learning and memory. Hillsdale, NJ: Erlbaum.

DEESE, J. (1959a). Influence of interitem associative strength upon immediate free recall. Psychological Reports, 5, 305-312.

DEESE, J. (1959b). On the prediction of occurrence of particular verbal intrusions in immediate recall. Journal of Experimental Psychology, $\mathbf{5 8}, 17-22$

DeEse, J. (1967). General psychology. Boston: Allyn \& Bacon.

EbBinghaus, H. (1964). Memory: A contribution to experimental psychology (H. A. Ruger \& C. E. Bussenius, Trans.). New York: Dover. (Original work published 1885 )

GARDINER, J. M., \& JAVA, R. I. (1993). Recognizing and remembering. In A. F. Collins, S. E. Gathercole, M. A. Conway, \& P. E. Morris (Eds.), Theories of memory (pp. 163-188). Hove, U.K.: Erlbaum.

HALLAM, A. (1973). A revolution in the earth sciences: From continental drift to plate tectonics. London: Oxford University Press.

JENKINS, J. J. (1970). The 1952 Minnesota word association norms. In L. J. Postman \& G. Keppel (Eds.), Norms of word association (pp. 1-38). New York: Academic Press

KeNT, G. H., \& RosanofF, A. J. (1910). A study of association in insanity. American Journal of Insanity, 67, 37-96, 317-390.

LINDSAY, D. S., \& READ, J. D. (1994). Psychotherapy and memories of childhood sexual abuse: A cognitive perspective. Applied Cognitive Psychology, 8, 281-338.

Madigan, S., \& O'HARA, R. (1992). Short-term memory at the turn of the century: Mary Whitton Calkins's memory research. American Psychologist, 47, 170-174.

MAYR, E. (1982). The growth of biological thought: Diversity, evolution, and inheritance. Cambridge, MA: Harvard University Press.

Merton, R. K. (1973a). Multiple discoveries as strategic research site. In N. W. Storer (Ed.), The sociology of science: Theoretical and empirical investigations (pp. 371-382). Chicago: University of Chicago Press. (Originally published as "Resistance to the systematic study of multiple discoveries in science," 1963, European Journal of Sociology, 4, pp. 237-249)

MERTON, R. K. (1973b). Singletons and multiples in science. In N. W. Storer (Ed.), The sociology of science: Theoretical and empirical investigations (pp. 343-370). Chicago: University of Chicago Press. (Originally published as "Singletons and multiples in scientific discovery," 1961, Proceedings of the American Philosophical Society, 105, pp. 470-486)

Miller, G. A. (1956). The magical number seven, plus or minus two: Some limits on our capacity for processing information. Psychological Revien, 63, 81-97.
Murdock, B. B., JR. (1962). The serial position effect in free recall. Journal of Experimental Psychology, 64, 482-488.

MYERS, D. G. (1986). Psychology. New York: Worth Publishers.

Neisser, U. (1967). Cognitive psychology. New York: AppletonCentury-Crofts.

Nelson, D. L., \& Roediger, H. L., III (Eds.) (1996). Memory illusions [Special issue]. Journal of Memory \& Language, 35(2).

Peterson, L. R., \& Peterson, M. J. (1959). Short-term retention of individual verbal items. Journal of Experimental Psychology, 58, 193-198.

Posner, M. I., \& KeEle, S. W. (1968). On the genesis of abstract ideas. Journal of Experimental Psychology, 77, 353-363.

Pressley, M., \& Grossman, L. R. (EDs.) (1994). Recovery of memories of childhood sexual abuse [Special issue]. Applied Cognitive Psychology, 6(4).

READ, J. D. (1993, December). From a passing thought to a vivid memory in ten seconds: A demonstration of illusory memories. Paper presented at the Clark University Conference on Memories of Trauma, Worcester, MA.

READ, J. D. (1996). From a passing thought to a false memory in 2 minutes: Confusing real and illusory events. Psychonomic Bulletin \& Review, 3, 105-111.

RoEDIGER, H. L., III (1996). Memory illusions. Journal of Memory \& Language, 35, 76-100.

RoEdiger, H. L., III, \& MCDERMotT, K. B. (1995). Creating false memories: Remembering words not presented in lists. Jounnal of Experimental Psychology: Learning, Memory, \& Cognition, 21, 803-814.

RoEdiger, H. L., III, MCDERMotT, K. B., \& RoBinson, K. J. (1998). The role of associative processes in creating false memories. In M. A. Conway, S. E. Gathercole, \& C. Cornoldi (Eds.), Theories of memory $I I$ (pp. 187-245). Hove, U.K.: Psychological Press.

Russell, W. A., \& Jenkins, J. J. (1954). The complete Minnesota norms for responses to 100 words from the Kent-Rosanoff Word Association Test (Tech. Rep. No. 11, Contract N8 ONR 66216, Office of Naval Research). University of Minnesota.

SARUP, G. (1978). Historical antecedents of psychology: The recurrent issue of old wine in new bottles. American Psychologist, 33, 478-485.

SCHACTER, D. L. (1982). Stranger behind the engram: Theories of memory and the psychology of science. Hillsdale, NJ: Erlbaum.

Schacter, D. L., Coyle, J. T., Fischbach, G. D., Mesulam, M. M., \& Sullivan, L. E. (EDs.) (1995). Memory distortion: How minds. brains, and societies reconstruct the past. Cambridge, MA: Harvard University Press.

Schacter, D. L., Eich, J. E., \& Tulving, E. (1978). Richard Semon's theory of memory. Journal of Verbal Leaning \& Verbal Behavior, 17 , $721-743$.

Tulving, E. (1968). Theoretical issues in free recall. In T. R. Dixon \& D. L. Horton (Eds.), Verbal behavior and general behavior theory (pp. 2-36). Englewood Cliffs, NJ: Prentice-Hall.

Tulving, E. (1976). Ecphoric processes in recall and recognition. In J. Brown (Ed.), Recall and recognition (pp. 37-73). London: Wiley.

Tulving, E. (1983). Elements of episodic memory. New York: Oxford University Press.

Tulving, E. (1985). Memory and consciousness. Canadian Psychologist, 26, 1-12.

UNDERWOOD, B. J. (1965). False recognition produced by implicit verbal responses. Journal of Experimental Psychology, 70, 123-129.

Waugh, N. C., \& Norman, D. A. (1965). Primary memory. Psychological Review, 72, 89-104.

\section{NOTES}

1. Citations of Deese (1959b) are overstated. At least three authors cited it by mistake when clearly they were referring to Deese (1959a). We have not adjusted the figures, however, because we cannot be certain that the corresponding error did not occur to a comparable degree in citations of Deese (1959a).

2. The correlation of .87 might seem inconsistent with the correlation of -.48 found in Deese's 1959a paper, but this reflects only different measures. The .87 coefficient indicates that the stronger the associative strength between list words and the critical word, the more likely it is that the critical word will intrude. The correlation of -.48 shows, on the 
other hand, that the higher the associative interrelatedness of a list of items, the less likely it is that an intrusion will occur. In the first instance, it is the associations between list words and intrusions that are measured; in the second, it is associations among the list items themselves that are measured.

3. We have only Deese's recollection of his difficulties with the Journal of Experimental Psychology to go on, though James Jenkins has provided corroborative testimony (personal communication, April 9 1997). We wish that we could have presented Melton's perspective, but our efforts to locate the editorial correspondence concerning the intrusion manuscript were unsuccessful.

4 . It is possible, of course, that many Bartlettians of the $1970 \mathrm{~s} \mathrm{sin-}$ ply did not know of Deese's (1959b) paper. But if so, we suspect that such ignorance stemmed from an awareness of Deese's methodological and theoretical orientation -that is, his use of word lists and his associative theoretical stance. As one of our correspondents, who was involved in research along the lines of Bartlett in the 1970s, said of Deese:

We saw such people as being constrained in their thinking by their roots in Ebbinghaus, whatever the particular research question they might attack. Hence I would not be likely to have read [Deese's] important paper even if I had learned that it referenced Bartlett. (J. Barresi, personal communication, January 29,1998 ).

(Manuscript received November 11, 1997; revision accepted for publication March 12, 1998.) 